\title{
Vivian Maier, la mirada de autor y la mirada social
}

\author{
Elsa Rodríguez Brondo
}

El descubrimiento reciente del archivo fotográfico de Vivian Maier, de más de 150,000 imágenes de Nueva York y Chicago de los años cincuenta, sesenta y setenta del siglo xx, nos descubre la vida callejera de la modernidad norteamericana. Este Atlas inmenso que nos legó una mujer que vivió y murió en el anonimato, nos permiten llevar a cabo una reflexión benjaminiana acerca de un momento del pasado que se manifiesta como el germen de nuestra reciente catástrofe. La fotografía de Maier no es el "pretexto" para emprender esta tarea, sino la prueba forense de un detective callejero, tal y como Benjamin concibió a la fotografía de finales del siglo XIX.

PALABRAS CLAVE: Fotografía, memoria, Walter Benjamin.

The recent discovery of the Vivian Maier photographic archive of over 150,000 images of New York and Chicago in the fifties, sixties and seventies of the twentieth century, reveals the street life of American modernity. This immense Atlas given tu us by a woman who lived and died in obscurity, allows us to perform a Benjaminian reflection on a time in the past that manifests itself as the germ of our recent catastrophe. Maier's photography is not the "pretext" to undertake this task, but the forensic evidence of a street detective, as Benjamin conceived photography in the late nineteenth century.

KEYWORDS: Photography, memory, Walter Benjamin.

Fecha de recepción: 6 de agosto de 2013

Fecha de aceptación: 20 de septiembre de 2013 



\section{Elsa Rodríguez Brondo \\ Universidad Nacional Autónoma de México \\ Instituto de Investigaciones Filológicas}

\section{Vivian Maier, la mirada de autor y la mirada social}

Vivian Maier (Estados Unidos, 1926-2009), ${ }^{1}$ como el coleccionista de Walter Benjamin, recorrió con su lente los años cincuenta, sesenta y setenta norteamericanos, en las ciudades de Nueva York y Chicago. De cada década conformó un mosaico de lo pequeño y cotidiano, siempre en el exterior, en sus calles. Especialmente, su mirada de los años cincuenta relampaguea como una alegoría del nacimiento de nuestra modernidad contemporánea: la ciudad habitada de vacío y espacio, ensimismada en sus estructuras de acero y hormigón, sus aparadores y sus líneas austeras; década de oficinistas de sombrero, cigarro y highball; de mujeres atrapadas en la tecnología del hogar o del trabajo, siempre servidumbre; niños que parecen habitar solitariamente las aceras; asfalto iluminado plenamente por la luz de un cielo diáfano todavía; emergencia de productos, comida rápida y viajes en transporte público. Eric Hobsbawm caracteriza esta época como los años dorados: "Durante los años cincuenta mucha gente, sobre todo en los cada vez más prósperos países 'desarrollados', se dio cuenta de que los tiempos habían mejorado de forma notable, sobre todo si sus recuerdos se remontaban a los años

${ }^{1}$ Todos los datos biográficos de Vivian Maier han sido recabados de los libros Maloof, Vivian Maier. Street Photographer y Cahan y Williams, Vivian Maier. Out of the Shadows, consultados en las respectivas secciones que ocupan en la página electrónica de Amazon (http://www.amazon.com). 


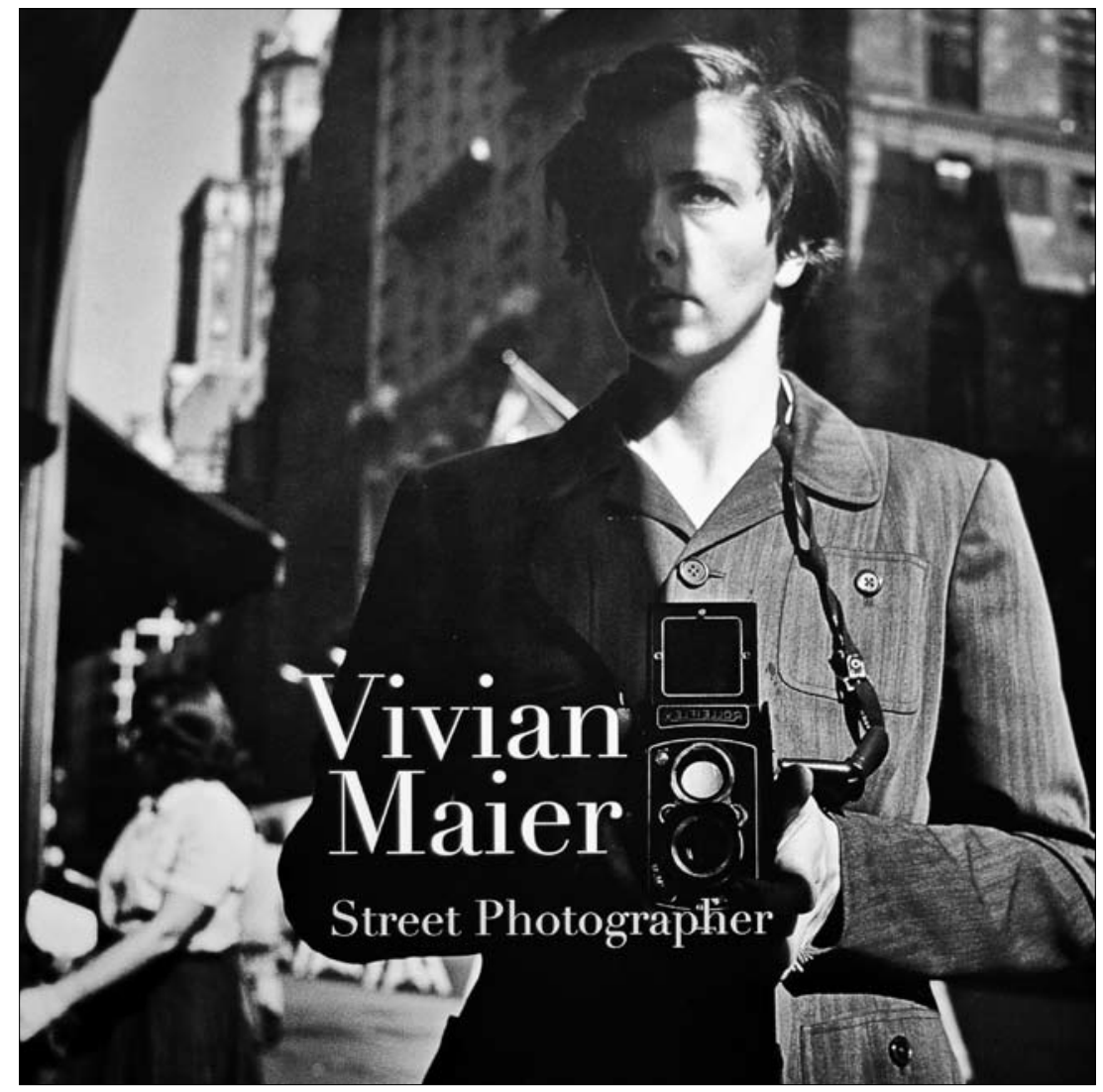

anteriores a la segunda guerra mundial" (Historia del siglo XX, 260). En las imágenes de Maier de los años cincuenta la guerra ha terminado, para volverse metafísica. Cierta banalidad se ha instalado en un mundo que se reconstruye en la destrucción, corriendo vertiginosamente hacia los placeres del estado de bienestar que apenas hoy se sostiene.

El caso de Vivian Maier podría considerarse un hito en la historia de la fotografía, tanto por el descubrimiento de su trabajo en años recientes (2007), como por el misterio que envuelve su vida. Resulta difícil creer que una mujer que se dedicó con pasión a la fotografía - se calcula que su obra está conformada por más de 120,000 negativos-, no haya publicado ni buscado publicar ninguna imagen en vida y que hubiese guardado celosamente el secreto de su oficio como fotógrafa, ejercien- 
do de niñera durante 40 años. Más allá del impacto mediático que su singular historia despierta, las imágenes de Maier constituyen una memoria fragmentada de la vida norteamericana de la segunda mitad del siglo xx y, por tanto, de una fracción clave de la memoria de Occidente. $\mathrm{Si}$, como señala Benjamin, París fue la capital del siglo XIX, la parte norte de Norteamérica lo fue a partir de las años treinta del siglo XX. Esta memoria del esplendor del derrumbe irrumpe en nuestros días, en un momento en donde el pasado se ha convertido en el depósito de la nostalgia y en producto de consumo bajo la etiqueta de vintage.

La aparición de su obra no es menos curiosa que la misma vida de Maier. En 2007, John Maloof, un joven corredor de bienes raíces, a la vez que historiador, asistió a una subasta de una bodega personal en Chicago, su dueña dejó de pagar el alquiler y había sido embargada. Ahí adquirió por unos dólares, junto con otros pocos compradores, una colección de negativos e impresiones que retrataban la vida cotidiana de su ciudad (Maloof, Vivian Maier. Street Photographer ). La cantidad de negativos y cartuchos era ingente, más de 100,000 imágenes por descubrir, así que decidió imprimir y revelarlas para financiar, a través de Internet, la conservación del archivo. Allan Sekula, un artista y crítico norteamericano, se puso en contacto con Maloof para hacerle notar la extraordinaria calidad de las imágenes que estaba vendiendo. Maloof recuperó las fotografías y emprendió el trabajo de investigación acerca de Vivian Maier. Un año y meses más tarde, en 2009, leyó en el obituario de un periódico de Chicago la esquela de Maier, quien había muerto en condiciones de pobreza el 21 de abril, ayudada en sus últimos años por tres de los otrora niños que había cuidado.

Actualmente se conocen las dos colecciones más importantes del trabajo de Vivian Maier, la de John Maloof, quien es poseedor del noventa por ciento de su obra y la de Jeffrey Goldstein, quien adquirió de otros de los compradores de la subasta 15,000 negativos en 2010. Cada uno de ellos ha capitalizado a su manera el acervo Maier: Maloof ha publicado los libros Vivian Maier. Street Photographer (2011) y Vivian Maier. SelfPortraits (2013), y realizó el documental Finding Vivian Maier (2013), además de impulsar exhibiciones de su colección en varios países de Europa y ciudades de Norteamérica. Por su lado, Jeffrey Goldstein auspició la publicación en 2012 de Vivian Maier. Out of the Shadows, editado por 
Richard Cahan y Michael Williams, y también promueve exhibiciones de su colección. Ambos comercializan impresiones profesionales de la obra de Maier, a través de galerías de arte neoyorkinas. El fenómeno de Vivian Maier es, sin duda, paradójico. En la medida en que ella preservó sus imágenes del mundo y se resistió a convertirlas en mercancía, sus coleccionistas han obtenido ganancias y exposición en los medios. La mina de oro apenas muestra sus primeras vetas, si tomamos en cuenta la cantidad de imágenes inéditas, las filmaciones, grabaciones de audio y documentos que quedan por ser clasificadas y expuestas. La figura de "objetualidad fantasmal" (Rühle, apud Benjamin, Libro de los pasajes, 201)² de Maier se cierne en el mercado del arte bajo el fetichismo de un descubrimiento inusitado, que despierta la curiosidad e invita al culto. En su materialidad, sobre toda conjetura de una vida que anima la fascinación del mercado, Maier llevó a cabo una empresa monumental, la construcción, durante treinta años, del archivo de una mirada.

El hecho de que Maier fuera una mujer fotógrafa no era una novedad en los años cincuenta, tampoco que fuera independiente desde los veintitantos años. Durante la Segunda Guerra Mundial Estados Unidos había utilizado la mano de obra femenina en oficios dedicados a los hombres, por razones operativas que nada tenían que ver con las reivindicaciones de las feministas de finales del siglo XIX. La mujer, después de haberse hecho cargo de una importante parcela de la producción en Norteamérica durante los años cuarenta, se incorporó al mundo laboral en la posguerra. Las mujeres excedentes se subsumieron en sus hogares, donde la promesa de un buen matrimonio, con casa en los suburbios y toda la tecnología doméstica a su alcance, más el atractivo de la hegemónica televisión, dibujaron el espejismo del que algunas huirían en las

${ }^{2}$ La extensa cita de Otto Rühle [tomada en el Libro de los pasajes de Benjamin del libro Karl Marx, Hellerau, 1928] explica la noción marxiana de fantasmagoría y fetichismo de la mercancía: "La mercancía parece a primera vista una cosa que se comprende por sí misma, algo trivial. Su análisis muestra que es algo retorcido, lleno de sutileza metafísica y de resabios teológicos”. En el caso de Vivian Maier, el descubrimiento de su obra no solo compete al mundo de arte y la academia por su calidad, sino que es un producto que se ha sacralizado por las circunstancias biográficas de la autora y el encuentro fortuito de su archivo. Los guardianes de sus imágenes no son museos o instituciones universitarias, sino particulares que tienen en Maier a una virgen milagrosa, de cuyo manto se hacen fragmentos para los feligreses-consumidores. 
siguientes décadas. Vivian Maier pudo haberse dedicado a un trabajo en el ámbito de la fotografía periodística o comercial. Incluso acceder con su talento al "sueño americano" de fama y prosperidad, pero no fue así. En su caso, la lógica capitalista no pudo ser el parámetro de sus expectativas o tal vez sí, pero a la inversa. Maier parece haber decidido el oficio de niñera en función de la situación de la mujer de clase media en su época. Es decir, en un estado de reclusión en la que se encontraban tanto las amas de casa, las obreras o las empleadas de oficina, ella optó por una tarea que le permitía deambular por las calles como un flâneur, ${ }^{3}$ sin la vigilancia de un jefe inmediato, en compañía y la complicidad de los niños.

Maier se inscribe en la estirpe de las mujeres fotógrafas que abundaron desde la difusión del daguerrotipo de los franceses Louis Daguerre y Joseph Niépce en 1839. Clementina Hawarden (1822-1865) o Julia Margaret Cameron (1815-1879) encabezan una lista importante ${ }^{4}$ si se compara con las pintoras de la misma época. Geneviéve Elisabeth Disdéri (1818-1878), esposa del famoso fotógrafo del Segundo Imperio francés, dirigió el estudio familiar de Brest cuando su marido se trasladó a París —en donde Disdéri se hizo famoso por sus tarjetas de presentación - y, años más tarde, montó su propio estudio en la ciudad luz. Para las primeras décadas del siglo xx, Gisèle Freund (1908-2000), socióloga y fotógrafa alemana, había reunido práctica y reflexión. Freund, que coincidió con Walter Benjamin en su exilio parisino de los años treinta, ocupará un lugar especial en el Libro de los pasajes y en

\footnotetext{
${ }^{3}$ Para Benjamin, la figura de flâneur del siglo XIX parisino es capital para ilustrar al intelectual que se encuentra fuera del contingente de las multitudes y deambula a placer entre las calles. A la vez que en movimiento, el flâneur representa una cesura y una afrenta al vértigo de una ciudad como París en la segunda mitad del siglo XIX: "El flâneur [...] legitima su paseo ocioso. Su indolencia es solamente aparente. Tras ella se oculta una vigilancia que no pierde de vista al malhechor. Y así es como el detective ve abrirse a su sensibilidad campos bastante anchurosos" ("El París del Segundo Imperio en Baudelaire", 55-56). "La calle conduce al flâneur a un tiempo desaparecido. Para él, todas las calles descienden, si no hasta las madres, en todo caso sí hasta un pasado que puede ser tanto más fascinante cuanto que no es su propio pasado privado" (Libro de los pasajes, 422 ).

${ }^{4}$ En la tercera edición del libro de Naomi Rosemblum, A History of Women Phtographers [New York, Abbeville Press, 2011] se consigna a 250 fotógrafas notables del mundo, desde el siglo XIX hasta nuestros días.
} 
La pequeña historia de la fotografía, sobre todo por dos obras que Benjamin conoció de primera mano: La fotografía en Francia en el siglo $X I X$, tesis con la que Freund obtuvo su doctorado de sociología en la Sorbona, publicado en 1936, y el manuscrito de su libro La fotografia desde el punto de vista sociológico que probablemente fuera el primer tratamiento de su célebre Fotografia y sociedad publicado hasta 1974. Freund fue un caso singular, porque su trabajo teórico tiene que ver con una comprensión de la práctica fotográfica, de su historia y de la reflexión acerca de su impacto social. ${ }^{5}$ Otras mujeres fotógrafas escribieron acerca de su oficio, por ejemplo, Julia Margaret Cameron (18151879), Tina Modotti (1896-1942) o Dorothea Lange (1895-1965), ${ }^{6}$ aun cuando no tuvieron los alcances teóricos de Freund. La fotografía realizada por mujeres en los años que preceden a la aparición de la obra de Vivian Maier, de casi un siglo, es prueba de que este oficio fue, desde la creación del daguerrotipo, un espacio de expresión artística mucho más abierta a la inclusión que otras prácticas culturales.

Vivian Maier y la célebre Diane Arbus (1923-1971) trabajaron en los mismos años y, de cierta forma, sus imágenes callejeras tienen la filiación de la estética del entorno urbano y el cuidado manejo del blanco y negro, pero el interés de Maier poco tiene que ver con el viaje que Arbus emprendió hacia las capas menos favorecidas de la sociedad norteamericana. Lo sórdido en el trabajo de Arbus es buscado y construido, a imagen y semejanza del trapero de Benjamin, ${ }^{7}$ en tanto Maier explora el mundo cotidiano, en donde encuentra todo tipo de personajes, como ante el espejo de un extraño. De las imágenes que ahora se conocen de

${ }^{5}$ Solo hasta los últimos años se puede hablar de otra fotógrafa-artista contemporánea-teórica: la inglesa Gen Doy.

${ }^{6}$ Textos tanto de estas fotógrafas como de Freund y Doy se publicaron en el Reino Unido en 1996, bajo el título Illuminations. Women Writing on Photography from the 1850 's to the Present. Liz Heron y Val Williams antologan no solo artistas de la imagen, sino a historiadoras y estudiosas del tema.

${ }^{7}$ Arbus, se sabe, no solo buscaba una empatía con los personajes que retrataba, sino que llegó a entablar una relación de años que quedó consignada en sus fotografías. Como un trapero que busca entre los desechos, Arbus atesoró el mundo de los olvidados. Para Benjamin, "trapero o poeta, a ambos les concierne la escoria; ambos persiguen solitarios su comercio en horas en que los ciudadanos se abandonan al sueño" ("El París del Segundo Imperio en Baudelaire”, 98). 
Maier, la mayor parte corresponden a instantáneas y retratos callejeros, pero sus numerosos autorretratos resultan una especie de correlato de ese mundo al que no parece pertenecer: espejos y reflejos en aparadores reproducen una y otra vez un rostro neutro, cuyos ojos buscan cierto sentido de identidad o pertenencia; en otros de sus autorretratos su sombra, que sustituye al rostro, se reproduce una y otra vez en diferentes superficies. Ver al mundo y verse a sí misma causa en el espectador la misma sensación de extrañeza y de distancia. Desafortunadamente, ni Maier ni Arbus tuvieron finales felices, pero este hecho no las une en lo particular sino que las inscribe en las estadísticas trágicas de la cultura. Benjamin, en su "Pequeña historia de la fotografía", relata los infortunios del francés Eugène Atget (1857-1927), otro fotógrafo del entorno urbano: "Vivió en París, pobre e ignorado; mal vendió sus fotografías a aficionados que apenas podían ser menos excéntricos que él, y hace poco ha muerto [4 de agosto de 1927], dejando una obra de más de cuatro mil fotos [...]. Alcanzó el polo de la suprema maestría enconada de un gran hombre que vivió siempre en la sombra, omitió plantar su bandera. Así no pocos creerán haber descubierto el polo que Atget pisó antes que ellos" (74).

Atget, como Maier, asistió a un cambio radical de la experiencia y también eligió la calle como escenario de su testimonio. Sus primeras fotografías de París datan de finales del siglo XIX y hasta los años veinte retrató meticulosamente su ciudad. El proyecto personal de Atget, que no estaba destinado a ser vendido, intentaba atrapar el tiempo que se desvanecía rápidamente, pero era un tiempo que estaba en la gente y los edificios, en las vitrinas y en la mercancía. Atget coleccionó todo lo que estaba destinado a desaparecer y al mismo tiempo a constituirse como síntoma permanente del capitalismo, la tenaz sustitución y destrucción de las cosas. Es verdad que el cambio radical de su ciudad había sucedido en 1852, cuando Napoleón III encargó a Haussmann, prefecto de una de las zonas de París, lo que Benjamin llama "el embellecimiento estratégico" (apud Löwy, "La ciudad, lugar estratégico del enfrentamiento", 182-183) de la urbe. Grandes avenidas, monumentos, plazas y parques se erigieron sobre las ruinas de una ciudad laberíntica y medieval, propia para ser tomada por los insurrectos. Haussmann se encargó de administrar la devastación de angostas y sinuosas calles, para erigir 
un espacio abierto para la belleza y la batalla. De lo poco que sobrevivió de aquel París íntimo y de su gente, Atget lo recuperó en sus imágenes. Su legado tiene una doble lectura, ser la memoria de los personajes y escenarios que estaban destinados a desvanecerse, pero también ser el diagnóstico del vértigo de la mercancía que se mostraba en los aparadores que Atget fotografió repetidas veces.

Maier gustaba también de los aparadores y las vitrinas; una de sus imágenes muestra a una mujer sorprendida detrás del vidrio de un locutorio, ella habla por un teléfono de pared, sentada frente a una mesa, está sola en un lugar destinado a realizar llamadas en soledad, pero el cristal que la separa de la calle la muestra a los transeúntes como un maniquí de escaparate. El reflejo en el vidrio de la misma Maier fotografiándola no hace más que enfatizar esa condición de las grandes ciudades en donde el aislamiento de las multitudes es tal, que aun a través de un vidrio transparente la gente se admira de ser vista. Maier fotografió las calles de Nueva York desde 1951, cuando regresó de Francia, donde pasó su segunda infancia y juventud, hasta 1956 cuando fijó su residencia en Chicago, lugar en donde desarrolló la mayor parte de sus trabajo. ¿Qué fue lo que encontró en Nueva York esta joven de 25 años, hija de una francesa y un austriaco, norteamericana de nacimiento, que a su llegada no hablaba una gota de inglés? En los años cincuenta, la fisonomía de las grandes ciudades del norte de Estados Unidos era impresionante. Nueva York se convirtió en el centro comercial del país durante las primeras décadas del siglo XIX. Para finales de ese siglo, la ciudad ya contaba con la infraestructura de una metrópoli acorde a los tiempos de un pujante capitalismo. En 1904 se estrenó el metro de la ciudad, solo a cuatro años de distancia del de París. Aunque la Gran Depresión de 1929 afectó al que ya era uno de los centros financieros del mundo, esto no impidió que el Edifico Chrysler, de 77 pisos, se inaugurara en 1930 y que once meses más tarde el Empire State se erigiera como símbolo de la supremacía norteamericana con sus 102 plantas (Nash, Manhattan Skycerapers, 61-65). Chicago, por su parte, tuvo una historia similar. En el siglo XIX, 1884-1885, se construyó el primer rascacielos del mundo, el Home Insurance Building, de tan solo diez pisos, pero su gran aportación a la ingeniería fue su técnica: la estructura de acero, usada por vez primera, serviría para la construcción de enormes edificios en 
los años siguientes. Estas novedades arquitectónicas son la sinécdoque de la expansión en todos los ámbitos de la economía y la cultura de Estados Unidos. Por otro lado, Chicago y Nueva York fueron ciudades de inmigrantes: la diáspora afroamericana, cobijada por las políticas abolicionistas en la segunda mitad del siglo XIX; la llegada de irlandeses, alemanes e italianos, por razones económicas, sobre todo durante el XIX; la paulatina y constante migración de latinoamericanos durante el XIX y $\mathrm{xx}^{8} \mathrm{y}$ la llegada de olas de inmigración europea, desde principios del siglo xx, magnificadas por la Segunda Guerra Mundial (Adams, Los Estados Unidos, 166-187).

En los años cincuenta, cuando Vivian Maier regresó a Norteamérica, Nueva York y Chicago — las ciudades más importantes del país junto con Los Ángeles - sumaban las aspiraciones de un progreso aparente, industriosas, glorificadas, cosmopolitas, multiétnicas y dispuestas a demostrar que encabezaban el boom económico de la posguerra en Occidente. No sorprende que la lente de Vivian Maier tomara la calle por asalto, en donde la vida pasaba de una manera veloz y extraordinaria. La presencia de los niños, privilegiados por Maier como modelos, mostraban diversas caras de la sociedad, pobres y ricos, negros, latinoamericanos, anglosajones; abandonados a su suerte o bien resguardados, bajo la vigilancia de sus niñeras. Una nueva infancia, huérfana de padres, estaba naciendo en un entorno de productividad y expansión. Sociólogos como Anthony Giddens ven en el modelo de las familias norteamericanas de los años cincuenta una etapa de transición: "Lo que en la mayoría de los países occidentales sus defensores llaman familia tradicional fue, en realidad, una fase tardía, transicional, en el desarrollo familiar durante la década de los cincuenta" (Un mundo desbocado, 70-71). Maier, a través de su lente, nos mostró que en grandes ciudades como Chicago y Nueva York, es justamente en esta década cuando se da un cambio radical en la sociedad. Como grandes centros financieros y productivos, la fuerza de trabajo de las mujeres era necesaria para construir el estado de bienestar, pero también ese mismo estado de bienestar

${ }^{8}$ La migración mexicana hacia los Estados Unidos se concentró en los estados fronterizos: California, Texas, Arizona y Nuevo México, sin embargo, durante las primeras décadas del siglo xx ya existían pequeñas comunidades de nuestro país en ciudades como Chicago o Nueva York (Durand y Arias, La experiencia migrante, 81-92). 
permitía a las amas de casa, de ciertas capas de la sociedad, delegar la maternidad en la servidumbre.

Maier fotografió un promedio de catorce imágenes por día, durante treinta años, y solo pudo imprimir 3000 . La cámara alemana Rolleiflex, una de las que usó Maier durante los años cincuenta, ${ }^{9}$ era de uso común para los fotógrafos de la época. Su sistema réflex, permitía visualizar la imagen tal y como era captada por uno de sus dos lentes y su gran formato de negativos de $6 \times 6 \mathrm{~cm}$, dotaba de una extrema calidad de definición (Busselle, El libro guía de la fotografía, 53). Las imágenes de Maier fascinan, entre otras cosas, por la calidad, definición, contraste y luminosidad, características que pertenecen a la técnica. Benjamin, en su conferencia de 1934, El autor como productor, ya había alertado sobre los riesgos de la moderna técnica fotográfica: “ ¿Y qué podemos ver? [La fotografía] Se vuelve cada vez más diferenciada, más moderna, y el resultado es que ya no puede reproducir una casa de vecindad, un montón de basura, sin sublimarlos [...] En efecto, con su procedimiento perfeccionado a la moda, la 'nueva objetividad' ha logrado incluso de la miseria un objeto de disfrute" (41). Maier eligió todo lo que las calles de Nueva York o Chicago podían ofrecer, su vida opulenta, la vejez, los niños, las mujeres, las vitrinas y también las penurias de los vagabundos y los granujas. En estos últimos "modelos", como menciona Benjamin, es difícil separar la belleza de la imagen, performativamente hablando, de una reflexión como la que emprendió Barthes, acerca de ese relato particular que se contaba. La emoción estética nos hace olvidar que en las grandes ciudades han sucumbido millones de personas sin techo o identidad, su presencia en el archivo Maier es una prueba forense de ello. Benjamin apostaba tanto en su conferencia del 34, como en la "Pequeña historia de la fotografia", por el pie de foto como una forma de abolir las fronteras entre escritura e imagen: "Lo que debemos exigir del fotógrafo es la posibilidad de dar a su placa una leyenda capaz de sustraerla del consumo de moda y de conferirle un valor de uso revolucionario" (El autor como productor, 42). Pero solo en el caso de un escritor que leyera a contrapelo de la fascinación de la técnica, y pudiera dar cuenta de lo que la modernidad ofrecía y ofrece como objeto de gozo.

\footnotetext{
${ }^{9}$ Se sabe exactamente qué tipo de cámaras usó gracias a sus autorretratos.
} 
Maier no podrá contarnos el relato de sus imágenes. Como en muchos casos del arte, queda para otros, nosotros, la tarea de una lectura de sus tres décadas de la vida norteamericana en las grandes urbes. ¿Pero no es acaso esta tarea la que también sugiere Benjamin en su Libro de los pasajes?, ¿no es esta la apuesta del historiador de arte alemán Aby Warburg en su Atlas Mnemosine de la supervivencia de ciertos rasgos del arte a través del tiempo? Maier, por supuesto, no realizó un trabajo de montaje como el de Benjamin y Warburg, pero dejó el material para llevarlo a cabo. Su enorme archivo podrá ser analizado desde muchas perspectivas: ser apropiado por la moda actual de la nostalgia de la forma; ser expuesto como fenómeno de feria: la "Mary Poppins fotógrafa"; volverse parte del archivo descomunal de la fotografía callejera, pero también ser el material privilegiado de un atlas de la más reciente modernidad. Una imagen dialéctica ${ }^{10}$ que nos señale que en ese entonces de las fotografías de Vivian Maier y este ahora hay un recuerdo que "relumbra en un instante de peligro" (Benjamin, Tesis sobre la historia, 40): los años cincuenta fueron una línea de arranque de otra, la misma, vertiginosa carrera hacia la catástrofe de la que somos partícipes.

\section{REFERENCIAS}

Adams, Willi Paul, Los Estados Unidos de América, México, Siglo XXI, 1979.

Benjamin, Walter, "El París del Segundo Imperio en Baudelaire", en Poesía y capitalismo. Iluminaciones II. Baudelaire, un poeta en el esplendor del capitalismo, Madrid, Taurus, 1972.

Benjamin, Walter, "Pequeña historia de la fotografía", en Discursos interrumpidos I. Filosofía de arte y de la historia, Madrid, Taurus, 1989.

Benjamin, Walter, El autor como productor, ed. Bolívar Echeverría, México, Ítaca, 2004.

Benjamin, Walter, Libro de los pasajes, ed. Rolf Tiedemann, Madrid, Akal, 2007.

${ }^{10}$ Walter Benjamin define así imagen dialéctica: "No es que el pasado arroje luz sobre lo presente, o lo presente sobre lo pasado, sino que imagen es aquello en donde lo que ha sido se une como un relámpago al ahora en una constelación. [...] Solo las imágenes dialécticas son auténticamente históricas” (Libro de los pasajes, 463). 
BenJamin, Walter, Tesis sobre la historia y otros fragmentos, ed. Bolívar Echeverría, México, Ítaca, Universidad Autónoma de la Ciudad de México, 2008.

Busselle, Michael, El libro guía de la fotografía, Barcelona, Salvat, 1980.

CAHAN, Richard y Michael Williams, Vivian Maier Out of the Shadows, New York, City Files Press, 2012.

DURAND, Jorge y Patricia Arias, La experiencia migrante. La iconografia de la migración México-Estados Unidos, México, Altexto, 2000.

Giddens, Anthony, Un mundo desbocado. Los efectos de la globalización en nuestros días, Madrid, Taurus, 2000.

Hobsвawm, Eric, Historia del siglo Xx. 1914-1991 [1995], Barcelona, Crítica, $10^{\mathrm{a}}$ ed., 2010.

Löwy, Michael, "La ciudad, lugar estratégico del enfrentamiento de clases. Insurrecciones, barricadas y haussmannización de París en el Passegen-Werk de Walter Benjamin", en Esther Cohen, ed., Walter Benjamin. Dirección múltiple, México, Universidad Nacional Autónoma de México, 2011.

Maloof, John, ed., Vivian Maier. Street Photographer, New York, Power House Books, 2011.

NASH, Eric Peter, Manhattan Skyscrapers, New York, Princeton Architectural Press, 1999. 